\title{
Assessment of Potential Thrombogenicity in an Animal Model of a Triple Viral Inactivated Factor IX Concentrate Manufactured in Argentina
}

\author{
Martinez MC' ${ }^{1}$ Rodriguez $\mathbf{R}^{1}$, Marinsaldi $\mathbf{A}^{1}$, \\ Rodriguez GR ${ }^{1}$, Guglielmone HA ${ }^{1,2 *}$, Bernardi \\ ME ${ }^{1}$, Valdomero $A^{3}$ and Cuadra GR $^{3}$ \\ ${ }^{1}$ National University of Cordoba, Products and Processes \\ Area, Blood Products Laboratory, Argentina \\ ${ }^{2}$ Department of Clinical Biochemistry, National \\ University of Cordoba, Argentina \\ ${ }^{3}$ Department of Pharmacology, National University of \\ Córdoba, Argentina \\ *Corresponding author: Hugo A Guglielmone, \\ National University of Córdoba, Product and Process \\ Development Area, Blood Products Laboratory, Av. \\ Juan Filloy s/n, Ciudad Universitaria Cordoba (X5000), \\ Argentina
}

Received: March 08, 2021; Accepted: April 09, 2021; Published: April 16, 2021

\begin{abstract}
The risk of thromboembolism with FIX replacement therapy remains a concern for hemophilic B patients. Previous studies from our laboratory demonstrated that the activated factor content of the FIX Plasma Derived (FIXpd) manufactured at UNC-Hemoderivados was negligible by in vitro assay. Despite this, we considered it important to conduct studies to assess the potential thrombogenic risk of our FIXpd concentrates using a modified stasis animal model.
\end{abstract}

FIXpd were inject doses of 100 or $200 \mathrm{IU} \mathrm{F} \mathrm{IX} \mathrm{kg}{ }^{-1}$ and some samples were supplemented with heparin ( $<0.5$ of heparin/ IU FIX). Eight rats were tested at each dose level in the presence or absence of heparin, considering those samples with a thrombogenicity $\geq 2.0$ as of potential thrombogenic risk.

The mean scores \pm SD 100 and $200 \mathrm{IU} \mathrm{kg}^{-1}$ in the presence or absence of heparin were $0.25 \pm 0.06$ and $2.25 \pm 0.45$ and $1.19 \pm 0.26$ and $2.81 \pm 0.40$, respectively. At both doses tested of FIXpd in the absence of heparin, there was no significant difference in mean scores $(P<0.05)$.

The encouraging data obtained from these animal experiments and results from in vitro tests, support the low thrombotic risk associated with the FIXpd concentrate manufactured in UNC Hemoderivados.

Keywords: Factor IX concentrates; Thrombogenicity; Animal models; Coagulation factor

\section{Abbreviations}

FIX: Factor IX; HB: Hemophilic B; FIXpd: Factor IX Plasma Derived; NAPTT: Non-Activated Partial Thromboplastin Times; Ph.Eur: European Pharmacopoeia

\section{Introduction}

Human factor IX (FIX) is a vitamin K-dependent glycoprotein that circulates in plasma at a concentration of approximately $5 \mathrm{ug} /$ $\mathrm{mL}$ [1]. The importance of this factor in the coagulation system is that a deficiency of FIX results in hemophilia B, a rare X-linked recessive bleeding disorder [2]. There is a broad spectrum of treatment possibilities for hemophilia B patients, including new, highly purified, plasma-derived factor IX (FIXpd) concentrates, and products using recombinant DNA technology $[3,4]$. The latter is expensive and the therapeutic options for developing countries are limited, so it is necessary to ensure optimum safety and efficacy as well as low costs for plasma-derived antihemophilic concentrates. The global survey report of the World Federation of Hemophilia showed that 21,500,000 IU of factor IX were used in Argentina in 2017, of which $75 \%$ was derived from human plasma [5]. One of the complications of these products reported in the literature is potential thrombogenic risk. FIXpd preparations may, unsurprisingly, contain other Glacontaining proteins including FVIIa and FX, although these were not detected in the highest purity plasma-derived products [6], as well as residual FIXa, which has been identified as a contaminant in both plasma-derived and recombinant FIX preparations [7]. The risk of thromboembolism with FIX replacement therapy remains a concern for hemophilic patients, their treating physicians, and the regulatory agencies. In July 2011, the European Medicines Agency began to require the monitoring and reporting of thrombotic events in clinical studies of new recombinant and human plasma-derived FIX products [8]. A recent study still showed a low rate of thrombotic events in patients with congenital factor deficiency receiving replacement factor products [9].

Previous studies from our laboratory demonstrated that the activated factor content of the FIXpd manufactured at UNCHemoderivados was negligible by in vitro assay using Non-Activated Partial Thromboplastin Times (NAPTT) in different pilot lots of factor IX concentrates compliant with the test required for European Pharmacopoeia (Ph.Eur). Despite this, we considered it important to conduct studies to assess the potential thrombogenic risk of our FIXpd concentrates using an animal model.

\section{Materials and Methods}

FIXpd was obtained from human plasma of healthy, fully screened donors. Triple virus reductions were applied by solventdetergent treatment, nanofiltration and dry-heat at $100^{\circ} \mathrm{C}$ for $30 \mathrm{~min}$. Chromatographic methods using ion exchange and affinity resins
Ann Hematol Oncol - Volume 8 Issue 5 - 2021

ISSN : 2375-7965 | www.austinpublishing group.com

Guglielmone et al. ( ) All rights are reserved
Citation: Martinez MC, Rodriguez R, Marinsaldi A, Rodriguez GR, Guglielmone HA, Bernardi ME, et al. Assessment of Potential Thrombogenicity in an Animal Model of a Triple Viral Inactivated Factor IX Concentrate Manufactured in Argentina. Ann Hematol Oncol. 2021; 8(5): 1343. 
were used to purify the FIX. The concentrate was formulated and placed in aseptically sterilized and lyophilized vials.

We used a modified stasis animal model [10] with rats instead of rabbits. Briefly, male Wistar rats (280-320 g) were anesthetized with an association of ketamine $(55 \mathrm{mg} / \mathrm{kg})$ and xylazine $(11 \mathrm{mg} /$ $\mathrm{kg}$ ) i.p., and laid in supine position. A 1-cm segment of the jugular vein was exposed through a midline central incision; the FIXpd $(0.5$ $\mathrm{mL}$ i.v. for $10 \mathrm{~s}$ in all cases) or sample control was given by the left cannulated femoral vein. The venous segment was tied off exactly $15 \mathrm{~s}$ after completing the infusion, remained in situ for 10 minutes and the development of thrombus in the isolated segment of jugular vein was determined by visual inspection using scores as reported by Wessler et al. [10]. All procedures were in accordance with the NIH Guide for the Care and Use of Laboratory Animals (National Research Council, USA, 2010) and the experimental protocols were approved by the Animal Care and Use Committee of the Facultad de Ciencias Químicas, Universidad Nacional de Córdoba, Argentina (Protocol Res. 1371/19). Every effort was made to minimize both animal suffering and their number.

FIXpd (600 \pm 120 IU per vial) was reconstituted to inject doses of 100 or 200 IU F IX kg-1. Some samples were supplemented with heparin to obtain $<0.5$ of heparin/IU FIX, according to the experimental design. As control (0 IU FIX $\left.{ }^{-1} \mathrm{~kg}^{-}{ }^{1}\right)$, we used sodium citrate buffer $\mathrm{pH}$ 7.4. For this study, eight rats were tested at each dose level (100 or $200 \mathrm{IU}$ F IX kg-1) in the presence or absence of heparin, considering those samples with a thrombogenicity $\geq 2.0$ as of potential thrombogenic risk.

A non-parametric analysis of variance (Kruskal-Wallis test) was used to compare the mean scores of infused FIXpd (100 or $200 \mathrm{IU} \mathrm{kg}$ $\left.{ }^{1}\right)$ in the presence or absence of heparin.

\section{Results and Discussion}

The mean scores \pm SD (deviation standard) for $100 \mathrm{IU} \mathrm{kg}^{-1}$ in the presence or absence of heparin were $0.25 \pm 0.06$ and $2.25 \pm 0.45$, respectively. For $200 \mathrm{IU} \mathrm{kg-}^{1}$ in the presence or absence of heparin, these values were $1.19 \pm 0.26$ and $2.81 \pm 0.40$, respectively. Finally, the negative controls in the presence or absence of heparin showed values of $0.25 \pm 0.04$ and $1.13 \pm 0.13$, respectively. The results are summarized in Figure 1.

At both doses of FIXpd (100 or $200 \mathrm{IU} \mathrm{kg}^{-1}$ ) in the absence of heparin, there was no significant difference in mean scores $(\mathrm{P}<0.05)$. At the dose of $100 \mathrm{IU} \mathrm{kg}^{-1}$, the presence of heparin induced a significant decrease in the mean score $(\mathrm{P}<0.001)$. However, the infusion of $200 \mathrm{IU} \mathrm{kg}^{-1}$ FIXpd containing heparin $<0.5 \mathrm{IU}$ induced a decrease in the mean score, which was not significantly different from its corresponding control (i.e. FIXpd $200 \mathrm{IU} \mathrm{kg}^{-1}$ in the absence of heparin, $\mathrm{P}>0.05)$. A similar pattern was found after sodium citrate buffer infusion (in the presence or absence of heparin).

The exact nature of the material(s) present in FIXpd concentrates responsible for inducing thrombogenic complications is unknown. In all lots of FIXpd manufactured in UNC-Hemoderivados, the NAPTT values found matched the Ph.Eur requirements, other vitamin K-dependent coagulation factors were absent, and the final product complied with the quality control requirements of the Factor

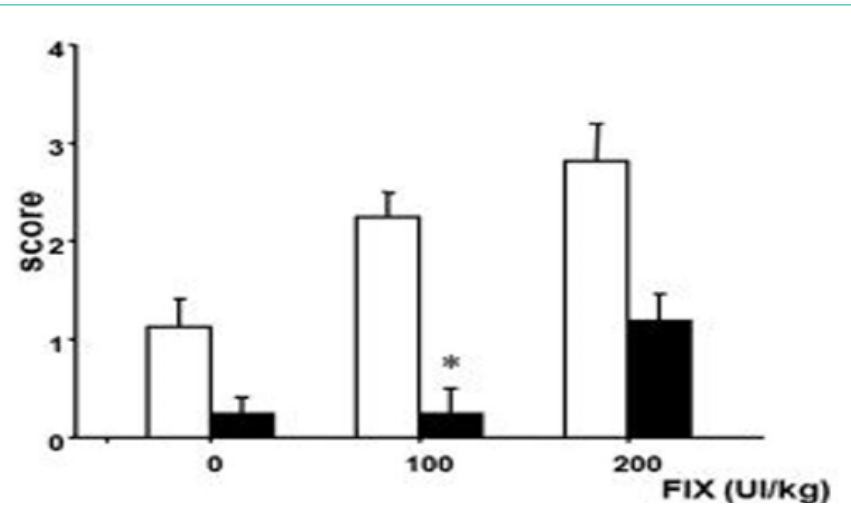

Figure 1: Mean thrombogenicity for 100 and $200 \mathrm{FIX} \mathrm{IU} \mathrm{kg}^{-1}$ in the absence (white) and presence (black) of heparin. At the dose of $100 \mathrm{IU} \mathrm{kg}^{-1}$, the presence of heparin induced a significant decrease in the mean score $(P<0.001)$.

IX (Human) monograph (01/2011:1223). Previous studies performed with Prothrombin Complex Concentrates (PCC) obtained in UNC Hemoderivados, in which we applied common purification steps to the FIXpd process, showed low thrombogenicity and also an absence of thromboembolic complications, as reported by our Pharmacovigilance department (product marketed since 2014) [11].

We used the stasis thrombus model to corroborate the in vitro results obtained in different lots of FIXpd concentrates and verified whether the addition of heparin improves the performance of this product. In effect, both doses (100 and $200 \mathrm{IU} \mathrm{kg}^{-1}$ ) of FIXpd without heparin induced a higher thrombogenicity, judging by the difference in the mean score with heparin present (mean score $<2$; $\mathrm{P}<0.001$ in dose $100 \mathrm{UI} \mathrm{kg}^{-1}$ in the presence or absence of heparin). Clinical trials conducted in patients with Hemophilia B, who received different treatment regimens or doses, including regular doses of $100 \mathrm{IU} /$ $\mathrm{kg}$, were consistent with unassociated thrombotic events or with clinically significant changes in the activation of coagulation markers during the course of replacement therapy with FIXpd [12].

\section{Conclusion}

The encouraging data obtained from these animal experiments, plus previous studies with PCC and results from in vitro tests, support the low thrombotic risk associated with the FIXpd concentrate manufactured in UNC Hemoderivados.

\section{Disclosure Statement}

The authors have no competing interests. MCM., RR, AM, DRR and MEB are employees of UNC Hemoderivados and AV., HAG. and GRC are employees of UNC.

\section{Acknowledgement}

Funding was provided by the UNC-Hemoderivados of the Universidad Nacional de Córdoba for blood products and experimental animals.

\section{References}

1. Stafford D. Extravascular FIX and coagulation. Thromb J. 2016; 14: 88-91.

2. Goodeve AC. Hemophilia B: molecular pathogenesis and mutation analysis. J Thromb Haemost. 2015; 13: 1184-1195. 
3. Peyvandi F, Garagiola I, Biguzzi E. Advances in the treatment of bleeding disorders. J Thromb Haemost. 2016; 14: 2095-2106.

4. Srivastava A, Brewer AK, Mauser-Bunschoten EP, Key NS, Kitchen S, Llinas A, et al. Guidelines for the management of hemophilia $2^{\text {nd }}$ edition. 2013.

5. Report on the Annual Global Survey 2017 World Federation of Hemophilia. 2018; 60.

6. Limentani SA, Gowell KP, Deitcher SR. High-purity factor IX concentrates for treatment of hemophilia $\mathrm{B}$ : relative purity and thrombogenic potential. Acta Haematol. 1995; 94: 12-17.

7. Gray E, Tubbs J, Thomas S, Oates A, Boisclair M, Kemball-Cook G, et al Measurement of activated factor IX in factor IX concentrates: correlation with in vivo thrombogenicity. Thromb Haemost. 1995; 53: 675-679.

8. Committee for Medical Products for Human use. Guideline on clinical investigation of recombinant and human plasma-derived factor IX products. London, United Kingdom: European Medicine Agency. 2011; 2-20.
9. Ekezue BF, Sridhar G, Ovasesov MV, Forshee RA, Izurieta HS, Selvam $\mathrm{N}$, et al. Clotting factor product administration and same-day occurrence of thrombotic events, as recorded in a large healthcare database during 2008 2013. J Thromb Haemost 2015; 13: 2168-2179.

10. Wessler S, Reimer SM, Sheps MC. Biological assay of a thrombosis-inducing activity in human serum. J Appl Physiol. 1959; 14: 943-946.

11. Minoldo S, Jara J, Guglielmone H. Complejo Protrombínico UNC, una nueva alternativa terapéutica: experiencia de uso en dos instituciones de Argentina. Hematologia. 2019; 23: 70-75.

12. Rendo P, Lamb J, Smith J, Fuiman J, Korth-Bradley J. Thrombogenicity evaluation in 221 patients with haemophilia B treated with nonacog alfa. Blood Coagul Fibrinolysis. 2018; 29: 81-86. 